\title{
The Role of Hyaluronic Acid Injection for the Treatment of Tendinopathy
}

\author{
A. Frizziero ${ }^{1}$, F. Vittadini ${ }^{2}$, D. Bigliardii ${ }^{1}$, C. Costantino ${ }^{1}$ \\ 1 Department of Medicine and Surgery, University of Parma, Parma, Italy \\ 2 Department of Physical and Rehabilitation Medicine, Casa di Cura Policlinico S. Marco, Venice, Italy
}

\author{
CORRESPONDING AUTHOR: \\ Antonio Frizziero \\ Department of Medicine and Surgery \\ via A. Gramsci 14 \\ University of Parma \\ Parma, Italy \\ E-mail: antonio.frizziero@unipr.it
}

DOI:

10.32098/mltj.04.2020.01

\begin{abstract}
SUMMARY
Hyaluronic acid has carved out an essential, though sometimes discussed, role in the treatment of joint degenerative pathology. Recent studies, first in vitro, then preclinical, have paved the way for use in tendon pathology. Clinical experience to date has shown extremely encouraging results in different tendinopathy frameworks such as tenosynovitis, insertional tendinopathies and tendon mid-portion.
\end{abstract}

\section{KEY WORDS}

Hyaluronic acid; injection therapy; tendinopathy; tendon pathology; tenocytes; therapeutic option.

\section{INTRODUCTION}

Hyaluronic acid (HA) plays a key role in the joints, where it maintains the functional and metabolic interaction between synovial membrane, synovial fluid, cartilage and, indirectly, subchondral bone.

In the past, this molecule was extracted from rooster combs after grinding and chemical treatment, while today is mainly produced through bacterial fermentation processes $(1,2)$.

Most of the physiological effects of exogenous HA and its viscosity depend primarily on the molecular weight of the molecule, consequently influencing its possible applications $(3,4)$.

Intra-articular hyaluronic acid (HA) injections are widely used in the conservative treatment of osteoarthritis and could delay surgical treatment $(5,6)$.

The efficacy is related to possible disease-modifying effects, secondary to modulation of inflammatory response and to the direct and indirect effect on synovial tissue, bone and cartilage (7-16).

Recently, the interest about the applications of HA in tendon pathologies is increasing. This could be in part related to the emerging preclinical evidences on the interaction with tenocytes and tendon behaviour and in part to the increased use of ultrasound (US). Indeed, US allows better accuracy, helping to achieve better outcomes also for less approachable locations. Our US-guided technique permitted a real-time visualization of the needle during the procedure, ensuring the correct distribution of the product, with low-risk of failure to inject in the desired area. In this brief editorial, we present, according to ethical standard of the journal (17), the state-of-art of the growing body of evidences in the field and the possible implications in clinical practice.

\section{IN VITRO AND PRE-CLINICAL STUDIES}

In recent years, several Authors have investigated the effects of HA on tendon cells relating to biomechanics, cell regeneration and proliferation.

Multiple findings support the role of HA in gliding resistance of tendon sheets decrease (18-21). The antiadhesive effect seems dose-dependent $(20,22)$.

Similarly, HA may determine increase tenocyte proliferation and vitality in a dose-dependent manner not related to molecular weight (23).

Anti-inflammatory properties of $\mathrm{HA}$ and its therapeutic biomolecular targets were also investigated.

Nakamura et al. compared the effects of corticosteroids and HA in human tendon fibroblasts from rotator cuff tears after surgical lesion. The Authors found that, both HA and corticosteroids induce anti-inflammatory and anti-adhesive effects on tendon and synovial fibroblast, whether cortico- 
steroid cause biomechanical weakening of the torn rotator cuff tendons, causing apoptosis of the tendon fibroblasts at the ruptured sites (24).

Po-Ting Wu et al. showed that high molecular weight HA significantly downregulated the $\mathrm{mRna}$ and protein expression of MMP-1 and 3 in a dose-dependent manner, two major endopeptidases implicated in pain generation and tendinopathy cleaving ECM proteins and collagen (25).

Osti et al. tested different HA formulations, observing that $\mathrm{HA}$ enhanced viability, proliferation and expression of collagen type $\mathrm{I}$ in tendon derived cells from $\mathrm{H}_{2} \mathrm{O}_{2}$-induced oxidative stress, decreasing cytotoxicity, reducing $\mathrm{Nrf} 2$ expression and enhancing catalase recovery (26).

Several trials focused on the ability of HA to decrease adhesion formation in different animal models (27-29).

In a model of Achilles tendon rupture, healing time in the HA group was shorter probably due to the early termination of the inflammatory phase (30). Furthermore, the repetitive administration of sodium hyaluronate during the Achilles-tendon healing process could regulate angiogenesis increasing VEGF and type 4 collagen expression (31).

Repeated peri-patellar injections of HA in detrained patellar tendon may limit detrained-associated damage in tenocytes and maintain tenocyte anabolic activity during detraining (32). In a second study, Frizziero et al. showed that repeated peri-patellar injections of HA may maintain e structural and functional properties of patellar tendon and enthesis in detrained rats $(33)$.

\section{CLINICAL STUDIES}

\section{Rotator cuff tendinopathy}

Meloni et al. found that ultrasound-guided HA injections in supraspinatus tendinosis may determine improvement in symptoms and disability until 9 months of follow-up compared to placebo (34).

Similarly, a 5-week HA injection protocol showed efficacy compared to placebo in rotator cuff partial tears in a placebo-controlled trial $(35,36)$.

Merolla et al. compared ultrasound-guided subacromial injections of HA and physiotherapy, founding that both treatments determine pain relief and clinical scores amelioration in the short term, while only HA group maintained a significant improvement at 12 weeks of follow-up (37).

Özgen observed that HA injection and physical therapy present similar effects in short and long term for supraspinatus tendinopathy (38). Flores et al. found that the combination of $\mathrm{HA}$ with an exercise protocol is superior to exercise only, leading to an earlier return to pre-injury activity and the need of less rehabilitation sessions (39). Frizziero et al. found that both HA and low-energy ESWT are effective in improving joint function and reducing pain in patients with non-calcific rotator cuff tendinopathy until 3 months of follow-up, with no clinically significant difference (40).

\section{Plantar fasciopathy}

Two recent studies evaluated the effects of $\mathrm{HA}$ on plantar fascia pathology. Kumai et al. found that 5 ha injections determine symptoms relief with a dose-dependent improvement (41).

Raeissadat et al. compared ultrasound-guided Injection of high molecular weight HA versus corticosteroid observing that both corticosteroid and HA were effective in improving pain and function and decreasing plantar fascia thickness. However, corticosteroids seem to have a faster trend in the short term with no significant difference 24 weeks after the treatment between the groups (42).

\section{Epicondylitis}

In the study of Petrella et al. patients that received HA injections had significantly greater improvement in VAS pain at rest and after grip testing than control placebo group, that persisted to 1 year follow up (43).

Khan et al. observed that a single injection is effective in management of moderate pain (VAS score $<7$ ), but not severe lateral epicondylitis (44).

Tosun et al. compared the effects of a combined HA- chondroitin sulphate injection versus a corticosteroid injection founding that both treatments were effective in reducing pain and improving function in short-term while HA was superior in long term follow-up (45).

\section{Achilles tendinopathy}

Lynen et al. compared safety and efficacy of 2 HA peritendinous injections respect to ESWT in mid-portion Achilles tendinopathy. HA injections showed greater outcome in short- and long-term with higher pain relief and function improvement until 6 months of follow-up (46).

Similarly, Fogli et al. and Frizziero et al. found that three US-guided HA injections induce prompt improvement in pain (NRS), symptoms and function (VISA-A, VISA-P and EQ-5D-5L) and US parameters $(47,48)$.

Good results were also reported in Ayyaswamy et al. with a single peritendinous injection of HA for non-insertional Achilles tendinopathy (49). 


\section{Patellar tendinopathy}

Kumai found that a single HA was effective and safe in patellar entesopathy a week after treatment (50).

In accordance to Achilles tendinopathy, Fogli et al. and Frizziero et al. found that three US-guided HA injections induce prompt improvement in pain (NRS), symptoms and function (VISA-A, VISA-P and EQ-5D-5L) and US parameters $(47,48)$.

Kaux et al. compared platelet-rich plasma injections and hyaluronic acid injections under US guidance, evidencing that even both treatments could ameliorate symptoms, PRP group had significant improvement in quadriceps strength while HA seemed to have a prompt effect in pain-relief (51).

\section{Tenosynovitis}

Callegari et al. examined the efficacy and safety of ultrasound-guided HA and corticosteroid injection and compared with open surgery for the treatment of trigger fingers. Injection therapy was associated with a shorter recovery time, with a consequent reduced absence from sports and work activities and fewer complications (52). In accordance, other Authors found that HA achieved similar effect as steroid injection in trigger finger with a long-lasting functional improvement (MHQ scores continued to increase in the HA group at 3 months follow-up) without adverse events, until 6 months of follow-up $(53,54)$.

Orlandi et al. compared the 6 months outcome of three different ultrasound guided percutaneous injection treatment for de Quervain's disease (steroid alone, steroid with saline, steroid with HA). At 6-month follow-up, patients

\section{REFERENCES}

1. Necas J, Bartosikova L, Brauner P, Kolar J. Hyaluronic acid (hyaluronan): a review. Veterinarni Medicina 2008;53:397-411.

2. Liu L, Liu Y, Li J, Du G, Chen J. Microbial production of hyaluronic acid: current state, challenges, and perspectives. Microb Cell Fact 2011;16;10:99.

3. Kaux JF, Samson A, Crielaard JM. Hyaluronic acid and tendon lesions. MLTJ 2016;13;5(4):264-9.

4. Pluda S, Pavan M, Galesso D, Guarise C. Hyaluronic acid auto-crosslinked polymer (ACP): Reaction monitoring, process investigation and hyaluronidase stability. Carbohydr Res 2016;433:47-53.

5. Jordan KM, Arden NK, Doherty M, et al. EULAR Recommendations 2003: an evidence based approach to the management of knee osteoarthritis: Report of a Task Force of the Standing Committee for International Clinical Studies Including Therapeutic Trials (ESCISIT). Ann Rheum Dis 2003;62:1145-1155.

6. Zhang W, Doherty M, Arden N, et al. EULAR evidence based recommendations for the management of hip osteoarthritis: treated with steroids and HA injections had significantly better VAS score, quick DASH score and retinaculum thickness compared to other groups (55).

\section{PERSPECTIVES}

Therapies for tendinopathies keep changing as research in this field progresses. To date, different injective substances have been investigated: platelet-rich plasma, high volume image-guided injections, hyaluronic acid, and prolotherapy, as a suitable option beside the commonly used eccentric loading rehabilitation regimen (56).

Preclinical and clinical findings appear to be promising for hyaluronic acid, especially for Achilles and patellar tendon pathology.

Considering that pre-clinical findings suggest dose-dependent effect and most of clinical studies used repeated injections protocol, it seems that more than 1 injection should be considered in clinical practice to maximize the efficacy. Actually, no clear indication about the correct molecular weight could be provided. In in vitro studies all the molecules were effective, while no comparison in clinical trials has never be performed to our knowledge. However, the rationale for HA in tendon is the possible effect on tendon cells, collagen structure and resistance gliding and we speculate that low to medium molecular weight may be prefer, considering that no "viscosupplementation" effect is necessary.

Further studies with large cohorts of patients for adequately long follow-up periods are needed to reinforce the present positive clinical results.

report of a task force of the EULAR Standing Committee for International Clinical Studies Including Therapeutics (ESCISIT). Ann Rheum Dis 2005;64:669-681.

7. Lisignoli G, Grassi F, Zini N, et al. Anti-Fas-induced apoptosis in chondrocytes reduced by hyaluronan: evidence for CD44 and CD54 (intercellular adhesion molecule 1) involvement. Arthritis Rheum 2001;44(8):1800-7.

8. Smith MM, Ghosh P. The synthesis of hyaluronic acid by human synovial fibroblasts is influenced by the nature of the hyaluronate in the extracellular environment. Rheumatol Int 1987;7(3):113-22.

9. Hirota W. Intra-articular injection of hyaluronic acid reduces total amounts of leukotriene C4, 6-keto-prostaglandin F1alpha, prostaglandin F2alpha and interleukin-1beta in synovial fluid of patients with internal derangement in disorders of the temporomandibular joint. Br J Oral Maxillofac Surg 1998;36(1):35-8.

10. Campo GM, Avenoso A, Nastasi G, et al. Hyaluronan reduces inflammation in experimental arthritis by modulating 
TLR-2 and TLR-4 cartilage expression. Biochim Biophys Acta 2011;1812(9):1170-81.

11. Kaneko S, Satoh T, Chiba J, Ju C, Inoue K, Kagawa J. Interleukin- 6 and interleukin-8 levels in serum and synovial fluid of patients with osteoarthritis. Cytokines Cell Mol Ther 2000;6(2):71-9.

12. Goto M, Hanyu T, Yoshio T, et al. Intra-articular injection of hyaluronate (SI-6601D) improves joint pain and synovial fluid prostaglandin E2 levels in rheumatoid arthritis: a multicenter clinical trial. Clin Exp Rheumatol 2001;19(4):377-83.

13. Yasui T, Akatsuka M, Tobetto K, Hayaishi M, Ando T. The effect of hyaluronan on interleukin-1 alpha-induced prostaglandin E2 production in human osteoarthritic synovial cells. Agents Actions 1992;37(1-2):155-6.

14. Shimizu M, Higuchi H, Takagishi K, Shinozaki T, Kobayashi T. Clinical and biochemical characteristics after intra-articular injection for the treatment of osteoarthritis of the knee: prospective randomized study of sodium hyaluronate and corticosteroid. J Orthop Sci 2010;15(1):51-6.

15. Gomis A, Miralles A, Schmidt RF, Belmonte C. Intra-articular injections of hyaluronan solutions of different elastoviscosity reduce nociceptive nerve activity in a model of osteoarthritic knee joint of the guinea pig. Osteoarthritis Cartilage 2009;17(6):798-804.

16. Altman RD, Manjoo A, Fierlinger A, Niazi F, Nicholls M. The mechanism of action for hyaluronic acid treatment in the osteoarthritic knee: a systematic review. BMC Musculoskelet Disord 2015;16:321.

17. Padulo J, Oliva F, Frizziero A, Maffulli N. Muscles, Ligaments and Tendons Journal - Basic principles and recommendations in clinical and field Science Research: 2018 update. MLTJ 2018;8(3):305-307.

18. Taguchi M, Zhao C, Sun YL, Jay GD, An KN, Amadio PC. The Effect of Surface Treatment Using Hyaluronic Acid and Lubricin on the Gliding Resistance of Human Extrasynovial Tendons In Vitro. J Hand Surg Am 2009;34:1276-1281.

19. Ikeda J, Zhao C, Sun YL, An KN, Amadio PC. Carbodiimide-derivatized hyaluronic acid surface modification of lyophilized flexor tendon: a biomechanical study in a canine in vitro model. J Bone Joint Surg Am 2010;92(2):388-95.

20. Sun YL, Yang C, Amadio PC, Zhao C, Zobitz ME, An KN. Reducing friction by chemically modifying the surface of extrasynovial tendon grafts. J Orthop Res 2004;22:984-989.

21. Nishida J, Araki S, Akasaka T, et al. Effect of hyaluronic acid on the excursion resistance of tendon grafts. A biomechanical study in a canine model in vitro. J Bone Joint Surg Br 2004;86:918-924.

22. Yamada T, Gotoh M, Nakama K, Mitsui Y, Higuchi F, Nagata K. Effects of hyaluronan on cell proliferation and mRNA expression of procollagens alpha 1 (I) and alpha 1 (III) in tendon derived fibroblasts from patients with rotator cuff disease: an in vitro study. Am J Sports Med 2007;35:1870-1876.

23. Gallorini M, Berardi AC, Berardocco M, et al. Hyaluronic acid increases tendon derived cell viability and proliferation in vitro: comparative study of two different hyaluronic acid preparations by molecular weight. MLTJ 2017;7(2):208-214 .

24. Nakamura H, Gotoh M, Kanazawa T, et al. Effects of corticosteroids and hyaluronic acid on torn rotator cuff tendons in vitro and in rats. J Orthop Res 2015;33:1523-1530.
25. Wu PT, Kuo LC, Su FC, et al. High-molecular-weight hyaluronic acid attenuated matrix metalloproteinase- 1 and -3 expression via CD44 in tendinopathy. Sci Rep 2017;7:40840.

26. Osti L, Berardocco M, di Giacomo V, Di Bernardo G, Oliva F, Berardi AC. Hyaluronic acid increases tendon derived cell viability and collagen type I expression in vitro: Comparative study of four different Hyaluronic acid preparations by molecular weight. BMC Musculoskelet Disord 2015;16:284 .

27. Liu Y, Skardal A, Shu XZ, et al. Prevention of peritendinous adhesions following flexor tendon injury with carbylan-SX, a semisynthetic glycosaminoglycan hydrogel. J Orthop Res 2008;26:562-569.

28. Zhao C, Wei Z, Kirk RL, et al. The Effects of Bio-Lubricating Molecules on Flexor Tendon Reconstruction in A Canine Allograft Model In Vivo. Plast Reconstr Surg 2014;133:628e-637e.

29. Jann HW, Hart JC, Stein LE, et al. The Effects of a Crosslinked, Modified Hyaluronic Acid (xCMHA-S) Gel on Equine Tendon Healing. Vet Surg 2016;45(2):231-9.

30. Liang JI, Lin PC, Chen MY, Hsieh TH, Chen JJ, Yeh ML. The effect of tenocyte/hyaluronic acid therapy on the early recovery of healing Achilles tendon in rats. J Mater Sci Mater Med 2014:25:217-227.

31. Halici M, Karaoglu S, Canoz O, Kabak S, Baktir A. Sodium hyaluronate regulating angiogenesis during Achilles tendon healing. Knee Surg Sports Traumatol Arthrosc 2004;12(6):562-7.

32. Salamanna F, Frizziero A, Pagani S, et al. Metabolic and cytoprotective effects of in vivo peri-patellar Hyaluronic acid injections in cultured tenocytes. Connect Tissue Res 2015;56:35-43.

33. Frizziero A, Salamanna F, Giavaresi G, et al. Hyaluronic acid injections protect patellar tendon from detraining-associated damage. Histol Histopathol 2015;30:1079-1088.

34. Meloni F, Milia F, Cavazzuti M, et al. Clinical evaluation of sodium hyaluronate in the treatment of patients with supraspinatus tendinosis under echographic guide: Experimental study of periarticular injections. Eur J Radiol 2008;68:170-173.

35. Wen-Yi C, Jih-Yang K, Feng-Sheng W, et al. Effect of sodium hyaluronate treatment on rotator cuff lesions without complete tears: A randomized, double-blind, placebo-controlled study. J Shoulder Elbow Surg 2010;19:557-563.

36. Moghtaderi A, Sajadiyeh S, Khosrawi S, Dehghan F, Bateni V. Effect of subacromial sodium hyaluronate injection on rotator cuff disease: A double-blind placebo-controlled clinical trial. Adv Biomed Res 2013;2:89.

37. Merolla G, Bianchi P, Porcellini G. Ultrasound-guided subacromial injections of sodium hyaluronate for the management of rotator cuff tendinopathy: a prospective comparative study with rehabilitation therapy. Musculoskelet Surg 2013;97(Suppl 1):49-56.

38. Ozgen M, Firat S, Sarsan A, Topuz O, Ardıc F, Baydemir C. Short- and long-term results of clinical effectiveness of sodium hyaluronate injection in supraspinatus tendinitis. Rheumatol Int 2012;32:137-144.

39. Flores C, Balius R, Álvarez G, et al. Efficacy and Tolerability of Peritendinous Hyaluronic Acid in Patients with Supraspinatus Tendinopathy: a Multicenter, Randomized, Controlled Trial. Sports Med Open 2017;3(1):22. 
40. Frizziero A, Vittadini F, Barazzuol M, et al. Extracorporeal shockwaves therapy versus hyaluronic acid injection for the treatment of painful non-calcific rotator cuff tendinopathies: preliminary results. J Sports Med Phys Fitness 2017;57(9):1162-1168.

41. Kumai T, Samoto N, Hasegawa A, et al. Short-term efficacy and safety of hyaluronic acid injection for plantar fasciopathy. Knee Surg Sports Traumatol Arthros. 2018;26(3):903-911.

42. Raeissadat SA, Nouri F, Darvish M, Esmaily H, Ghazihosseini P. Ultrasound-Guided Injection of High Molecular Weight Hyaluronic Acid versus Corticosteroid in Management of Plantar Fasciitis: A 24-Week Randomized Clinical Trial. J Pain Res 2020;13:109-121.

43. Petrella RJ, Cogliano A, Decaria J, Mohamed N, Lee R. Management of Tennis Elbow with sodium hyaluronate periarticular injections. Sports Med Arthrosc Rehabil Ther Technol 2010;2:4.

44. Khan IU, Awan AS, Khan AS, Marwat I, Meraj M. Efficacy Of A Single-Injection Sodium Hyaluronate Treatment In Lateral Epicondylitis. J Ayub Med Coll Abbottabad 2018;30(1):85-89.

45. Tosun HB, Gumustas S, Agir I, et al. Comparison of the effects of sodium hyaluronate-chondroitin sulphate and corticosteroid in the treatment of lateral epicondylitis: a prospective randomized trial. J Orthop Sci 2015;20(5):837-43

46. Lynen N, De Vroey T, Spiegel I, Van Ongeval F, Hendrickx NJ, Stassijns G. Comparison of Peritendinous Hyaluronan Injections Versus Extracorporeal Shock Wave Therapy in the Treatment of Painful Achilles' Tendinopathy: A Randomized Clinical Efficacy and Safety Study. Arch Phys Med Rehabil 2017;98(1):64-71.

47. Fogli M, Giordan N, Mazzoni G. Efficacy and safety of hyaluronic acid $(500-730 \mathrm{kDa})$ Ultrasound-guided injections on painful tendinopathies: a prospective, open label, clinical study. MLTJ 2017;7(2):388-395.

48. Frizziero A, Oliva F, Vittadini F, et al. Efficacy of ultrasound-guided hyaluronic acid injections in achilles and patellar tendinopathies: a prospective multicentric clinical trial. MLTJ 2019;9(3);305-313.

49. Ayyaswamy B, Vaghela M, Alderton E, Majeed H, Limaye R. Early Outcome of a Single Peri-Tendinous Hyaluronic Acid Injection for Mid-Portion Non-Insertional Achilles Tendinopathy - A Pilot Study. Foot (Edinb) 2020:101738.

50. Kumai T, Muneta T, Tsuchiya A, et al. The short-term effect after a single injection of high-molecular-weight hyaluronic acid in patients with enthesopathies (lateral epicondylitis, patellar tendinopathy, insertional Achilles tendinopathy, and plantar fasciitis): a preliminary study. J Orthop Sci 2014;19(4):603-11.

51. Kaux J-F, Bornheim S, Dardenne N, et al. Comparison between platelet-rich plasma injections and hyaluronic acid injections in the treatment of patellar tendinopathies: a randomized trial. MLTJ 2019;9(3):322-327.

52. Callegari L, Spanò E, Bini A, Valli F, Genovese E, Fugazzola C. Ultrasound-guided injection of a corticosteroid and hyaluronic acid: a potential new approach to the treatment of trigger finger. Drugs R D 2011;11(2):137-45.

53. Liu D-H, Tsai M-W, Lin S-H, et al. Ultrasound-Guided Hyaluronic Acid Injections for Trigger Finger: A Double-Blinded, Randomized Controlled Trial. Arch Phys Med Rehabil 2015;96(12):2120-7.

54. Kanchanathepsak T, Pichyangkul P, Suppaphol S, Watcharananan I, Tuntiyatorn P, Tawonsawatruk T. Efficacy Comparison of Hyaluronic Acid and Corticosteroid Injection in Treatment of Trigger Digits: A Randomized Controlled Trial. J Hand Surg Asian Pac Vol 2020;25(1):76-81.

55. Orlandi D, Corazza A, Fabbro E, et al. Ultrasound-guided percutaneous injection to treat de Quervain's disease using three different techniques: a randomized controlled trial. Eur Radiol 2015;25(5):1512-9.

56. Aicale R, Bisaccia RD, Oliviero A, Oliva F, Maffulli N. Current pharmacological approaches to the treatment of tendinopathy. Expert Opin Pharmacother 2020;21(12):1467-1477. 